\title{
Us and Mri Neurography Assessment of Diagnostic Criteria in Patients With Carpal Tunnel Syndrome Using Electrophysiological Tests as Gold Standard: A Prospective Study
}

Mona Gamalludin AlKaphoury ( $\nabla$ dr.monakaphoury@hotmail.com )

Ain Shams University

Eman Farouk Dola

Ain Shams University

\section{Research Article}

Keywords: Magnetic resonance neurography (MRN), Carpal tunnel syndrome, Ultra sound (US), Median nerve cross sectional area (CSA), Bowing and flattening indices

Posted Date: January 14th, 2022

DOI: https://doi.org/10.21203/rs.3.rs-1191587/v1

License: (c) (1) This work is licensed under a Creative Commons Attribution 4.0 International License.

Read Full License 


\section{Abstract}

\section{Background}

Peripheral neuropathy evaluation depends mainly on physical examination, patient history, electrophysiological studies, with evoked potential abnormalities. High-resolution US has the advantage of being fast, non-invasive modality with nerve dynamic assessment allowing examination of long part of nerve. MR imaging serve better in examination of deeper nerves with higher contrast resolution. It shows great benefit in patient with atypical presentation, Equivocal diagnosis and suspicious of secondary cause and post-surgical relapse.

Methods

This study was conducted prospectively on 32 patients, presented with carpal tunnel syndrome diagnosed by electrophysiological tests. Superficial US of the wrist joint was done to all participants followed by MRI within 1 weeks of the US.

We aimed to assess the measurements \& criteria of both US \& MRN in diagnosis of CTS, depending mainly on the three-measurement assessed by Buchberger et al., then to find the agreement between US \& MR Neurography (MRN)

Results

Us proved to have higher rate of CTS prediction, the three main parameters CSA measurement, distal nerve flattening and flexor retinaculum bowing indices showed positive occurrence of $93.7 \%, 59.4 \%$ $\& 59.4 \%$ respectively. While we found that decreased nerve echotexture was positive in $90.6 \%$ of patients.

Regarding MRI it showed less diagnostic ability when using CSA measurement as it was positive in $81.2 \%$ of patients, also distal tunnel nerve increased flattening and bowed flexor retinaculum positive results were slightly decreased to $56.2 \%$ for each. In contrast to high T2 signal of median nerve which was positive in $90.6 \%$ of patients.

In agreement study, we found statically significant difference supporting US as the primary diagnostic modality of CTS depending mainly on the three measurement CSA, Flattening and bowing indices. Yet, for cases of secondary CTS and detection of underlying entrapping cause as well as innervated muscle early abnormality detection and better tissue characterization, MRI was better diagnostic modality with statistically significant difference.

\section{Conclusions}

Our results proved that ultrasound examination can be used as first imaging modality after physician evaluation with comparable results to electrophysiological studies in evaluating CTS and try to find the cause. MRN examination came as second step in patients with suspected muscle denervation changes 
that could not be elicited by US or equivocal cases for detection of secondary cause in clinically suspected patient.

\section{Background}

Neuropathy is a clinical term describing both sensory and motor abnormalities at areas supplied by specific peripheral nerve, it may be caused by metabolic disorders or by regional structural disorders. Carpal tunnel syndrome (CTS) represents the most common peripheral neuropathy of the upper extremities with Prevalence average 2 to $3 \%$ in the general population (1)

Many risk factors were described as cause of CTS; the most common factor is Diabetes mellitus. Others include pregnancy (which can resolve after delivery), rheumatoid arthritis, obesity, acromegaly, hypothyroidism, metabolic depositional disease like gout, calcium pyrophosphate deposition, amyloidosis, and mucopolysaccharidosis (in children). CTS could also be induced by external compression as accessory muscles, tendons synovitis or wrist masses i.e., ganglion cyst, hamartoma, and lipoma or surrounding tissue masses (2)

Nerve compression induces a cascade of pathophysiological changes mainly due to microcirculatory disorder. In early stages, compression will affect mainly the axonal transport which leads to symptomatic reversible damage. Later, the interstitial edema of the epineurium and endoneurium would cause consequent nerve damage starting with its sheath, giving recurrent symptoms) followed by damage of the axon which cause the denervation signs (muscle weakness and sensory abnormalities). At chronic stages, edema activates fibroblast and lead to fibrosis of supporting tissue. If CTS treatment fail, it should raise the possibility of Double crush syndrome, which states that if the nerve proximally compressed, its distal part is more liable to be compressed and vice versa (3)

Peripheral neuropathy clinical evaluation depends mainly on physical examination, patient history \& electrophysiological studies with evoked potential abnormalities (4). Conduction studies used mainly to diagnose the regional median nerve injury and the degree of nerve damage as well as both distal sensory nerve conduction velocities and motor latency abnormalities (5)

High-resolution US has the advantage of being fast \& non-invasive modality, added to this the nerve dynamic assessment with high spatial resolution and allowing examination of long part of nerve. Its main limitation is being operator dependent. (6)

MR imaging serve better in examination of deeper nerves with higher contrast resolution. It shows great benefit in patient with atypical presentation, equivocal diagnosis, suspicious of secondary cause and post-surgical relapse. (7)

\section{1-1. Ultrasonography diagnostic criteria:}

US is used in cases with normal electrophysiological tests with early disease stage (8). As, in early disease, the US nerve morphological changes precede its electrophysiological abnormalities. (2) 
Carpal tunnel syndrome US diagnostic features include:

1- Different caliber seen as proximal enlargement of median nerve followed by distal flattening (Notch sign). Nerve constriction beneath flexor retinaculum, giving hour glass appearance. In few cases distal nerve enlargement could be noted with limited nerve motion in sagittal plane [9]

2- Increased nerve CSA at pisiform and scaphoid level. Normal cross section ranges from 6.1 to $10.4 \mathrm{~mm}$. Cross sectional area of $12 \mathrm{~mm}^{2}$ has $99 \%$ sensitivity, while $8.5-12 \mathrm{~mm}^{2}$ showed $87 \%$ sensitivity in diagnosis of carpal tunnel syndrome with proportional relationship between increases CTA and nerve conduction velocity reduction (10). Patients with bifid nerves have cross sectional area of $12 \mathrm{~mm} 2$ calculated by adding the CSA of both its medial and lateral branches (11).

3- Flexor retinaculum palmer bowing with a value of $\geq 2-4 \mathrm{~mm}$ can be used in diagnosis of CTS (12)

4- Fattening index, the ratio between greatest and smallest diameter of the nerve, if it is over 3. (12)

5- Hypoechoic nerve with loss of fasciculated appearance (3)

6- Intraneural hyperemia due to congestion of epi \& endo neural veins by the compressed nerve (2).

7- Extrinsic compressive mass could be detected by US as accessory muscles, ganglion cysts or related soft tissue tumors. Routine whole length scanning of the nerve, "lift" technique, should be done systemically (3)

8- Dynamic flexion-extension of fingers US examination shows reduced transverse nerve mobility under flexor retinaculum due to compression. (3)

\section{1-2 MR imaging diagnostic criteria:}

1- Hyperintense signal noted in nerve fibers at fluid-sensitive sequences.

2- increased nerve caliber at pisiform bone level.

3- Palmar aponeurosis bowing volary with nerve flattening at hook of hamate level

4- Denervation edema of muscle followed by atrophy could be uncommon sequel in severe cases of CTS $\&$ chronic situation. Also, could be noted in cases with distal carpal tunnel entrapment of recurrent branch.

5- Carpal tunnel mass may involve pathognomonic lesions i.e lipomatosis of the nerve of the nerve or peripheral nerve soft tissue neoplasms (4). (Case 1)

\section{Methods}


This study was conducted prospectively on 32 patients, presented with carpal tunnel syndrome diagnosed by electrophysiological tests, after approval of Ain Shams University Ethical Committee with Informed written consent taken from patients or guardians of patients who were invited to participate in the research.

The following exclusion criteria were utilized:

1-Patients with previous surgical intervention of the median nerves or wrist joint.

2-Patient with complaint of brachial plexus entrapment syndromes (to exclude high level entrapment)

3-Patients with contraindications for MRI e.g., an implanted pacemaker.

4- evidence of polyneuropathy or radiculopathy

5-electrodiagnostic studies showed associated peripheral neuropathy.

2-1 Imaging protocol:

- Superficial US of the wrist joint was done to All participants by using superficial Ultrasonography set (Toshiba, Philips), high resolution probe of $7.5-10 \mathrm{MHz}$ frequency. Patients were examined in seating position, with their face to the examiner showing extended arms and supinated forearm with examined the wrist on the table of examination. Both metacarpophalangeal and proximal interphalangeal joints mildly flexed. Imaging both long and short axis of median nerve were taken using carpal bones as landmarks.

- MRI was performed within 1 weeks of the US to ensure no interval change, using 1.5-Tesla [Achiva-Philips, Germany]. we used a phased array surface coil on the wrist region. Small Field of View (FOV) [5-10cm] was applied for high spatial resolution using the following sequences:

1-Axial T1 SE-weighted image [2-3mm] for anatomical baseline, and isotropic reconstruction.

2-Axial T2 FS, T2 SPAIR weighted images [ $3 \mathrm{~mm}$ ] for pathological correlation.

3-3D SPAIR images [1 $1 \mathrm{~mm}$ ] with Sampling Perfection and Application optimized Contrast [SPACE] post-acquisition processing including; - MPR, MIP, and curved planner reconstruction.

4- 3D DW PSIF image with fat suppression (reversed fast imaging with steadystate-free precession) with selective suppression of all moving structure [vessel].

No contrast media is required except if super added inflammation was suspected. 


\section{2-2 Image analysis:}

Images will be assessed by same methods and equations for both MRI \& US regarding:

1- CSA (cross sectional area) is Calculated proximal to tunnel (scaphoid pisiform level) using ellipse formula [(maximum AP diameter) $\times$ (maximum LL diameter $) \times(\pi / 4)]$, normal less than $10 \mathrm{~mm} 2$.

2-flattening index is calculated as a ratio between nerve transverse axis to its AP axis (flattening ratio) (D1/D2) should be less than 3.

3-Bowing index of flexor retinaculum measured at the (hamate-trapezium level), a line is drawn connecting trapezium tubercle and hook of the hamate, then the distance from this line to most anterior part of transverse carpal ligament is calculated, Normally the distance is less than $4 \mathrm{~mm}$. (bowing index means AP distance /transverse distance, it should not exceed 15\%)

4- Nerve echo textural changes in US, and T2 signal intensity, fascicular pattern of the compressed median nerve in MRI was reported as well as the innervated muscles. The compressed nerve becomes uniformly hypoechoic in US and of high T2 signal in MRI with disrupted the fascicular pattern. The presence or absence of masses should be noted.

\section{Results}

\section{3-1 Statistical Analysis}

The sex, age and the numbers of right and left wrists examined were tabulated.

The diagnostic agreement between US \& MRI in patient with tunnel syndrome was tabulated by using CSA, Bowing and flattening indices as well as nerve textural changes and identified underlying causes.

All statistical tests were performed with Spss (Statistical package for social science), version 20. Quantitative analysis was introduced as mean and standard deviation. Qualitative analysis was introduced as numbers and its related percentages. Chi square test was used to compare between qualitative variables.

One-way ANOVA was used to compare between more than two independent means. Pearson formulae was used to record quantitative variables relationship

\section{3-2 Demographic data:}

A thirty-two CTS diagnosed patients with age ranging from 18.00-67.00 \& 43.25 mean age, confirmed by Electrophysiological testing using Electromyography (EMG) and Nerve conduction velocity, were enrolled in our study. More than third of patients were suffering from mild CTS (34.4\%), about third of patients were diagnosed as minimal neuropathy and quarter of them were diagnosed as moderate neuropathy. Thenar Muscle wasting found in more than fourth of patients (28.1\%). (Table 2) 
The participants were categorized as 20 out 32 females (62.5\%) and 12 males. 26 of patients had right sided affection (81.2\%) and 6 with left sided affection .16 of patients worked as housewives, 11 handworkers, 2 gymnast, 2 employee and one nurse. All the patients complained of wrist pain with 21 out of them complained of hand parathesis (65.6\%) (Table 1$)$.

In our study, the majority of the patient showed no associated comorbidities (20 out of $32,62.5 \%$ ). In patients with co-morbidities, diabetes mellites was the commonest followed by rheumatoid arthritis. Two of our patients had wrist cut wounds (Table 1).

\section{3-3 US finding:}

Increased CSA was positive finding in 30 out of 32 patients representing $93.7 \%$ of patients while $59.4 \%$ of our patients showed synchronous increase in both distal nerve flattening and flexor retinaculum bowing indices.

29 out of 32 showed decrease nerve echotextures (90.6\%) \& only 2 patients showed muscle atrophic changes by US.

Us could detect underlying causes in 10 patients. 6 of them showed flexors tenosynovitis, 2 with synovial hypertrophy and 2 had post traumatic NIC (Neuroma in continuity). (Table 3) (Figure 1)

The mean CSA calculated in our study was $(14.96 \mathrm{~mm} 2+/-4.2)$ ranging (4 -24 mm2), mean bowing index was $15.11+/-4.42$ _ ranging $(8.32-27.00)$ and the mean flattening index was $2.97+/-0.69$ and ranged $1.54-4.20$ (Table4)

\section{3-4 MRI finding}

MRI could detect increased CSA in 26 out $32(81.2 \%)$ of the patients, while distal tunnel nerve flattening and bowed flexor retinaculum were seen in 18 patients $(56.2 \%)$ for each

Increased nerve T2 signal could be elicited at 29 out 32 patients $(90.6 \%)$ with only 3 patient shows disrupted fascicular pattern. Muscle denervation signal alteration was seen in $34.4 \%$ of patients.

MRI could detect underlying tunnel abnormalities in 15 patients. 8 of them with flexors tenosynovitis, two had traumatic neuroma, three with ganglion cyst and two showed deep interstitial edema of carpal tunnel. (Table 5) (Figure 2)

\section{3-5 Agreement study between MRI and US measurements:}

Increased CSA in both MRI \& US were was positive in $93.8 \%$ \& $81.2 \%$ of patients respectively denoting higher US correlation compared to MRI with statistically significant finding (P value 0.02 ). (Table 6,7 \& 8)

Also, the increase in both bowing and flattening indices were detected in $59.4 \%$ of patients for each using US compared to $56.2 \%$ of patients using MRI, denoting highly significant statistical variability ( $p$ value 
Underlying local causes were detected at $31.25 \%$ of patients by US compared to $46.8 \%$ of cases using MRI. Two patients of tenosynovitis and 3 patients with ganglion cysts were missed sonographically, denoting highly statistically significant finding ( $p$ value 0.001 ) (Table 9 ).

\section{Discussion}

The term "Entrapment syndrome" is used to describe neuropathic changes due to local structural abnormality or intrinsic nerve lesions (13). Electrophysiological testing and clinical examinations are the corner stones in diagnosis of CTS and can be used as gold slandered to detect efficacy and sensitivity of other diagnostic modalities (14) In our study all included patients were diagnosed based on clinical signs confirmed with electrodiagnostic examinations.

US used as noninvasive modality for assessment of nerve entrapment with advantage of real time, high resolution, low cost and dynamic imaging, yet drawbacks were being operator dependent and sometimes difficult if images degraded by shadowing and tissue distortion as in cases of scarring and local injury (15). The compression of median nerve at carpal tunnel leads to consequent flattening of nerve with swelling of its proximal part, causing endo-neural edema. This was the reason for using the CSA as measurement for diagnosis of CTS, yet later on, other measurements were added by Buchberger et al., which include flattening ratio and bowing index. (19)

In our study, we aimed to assess measurements \& criteria of both US \& MRI in diagnosis of CTS, depending mainly on the three-measurement assessed by Buchberger et al., then to find the agreement between US \& MR Neurography (MRN).

In previous studies, the CSA cut off value ranged from 6.1 to $10.4 \mathrm{~mm} 2$ with such $4.3 \mathrm{~mm} 2$ difference of both normal values $(4.3 \mathrm{~mm} 2)$ represent $51 \%$ of normal CSA of median nerve $(8.4 \mathrm{~mm} 2)$ (16). Yesildag et al., 2004 (23) concluded that US measurements of median nerve CSA was the most predictive measurement for CTS with cut off value $10.5 \mathrm{~mm} 2$ at proximal tunnel level, providing a diagnostic sensitivity and specificity of $89 \%$ and $94.7 \%$ respectively. Compared to Buchberger et al., who mentioned that the mean CSA of $14.5 \mathrm{~mm} 2$ in CTS patients and $7.9 \mathrm{~mm} 2$ in control group, and Duncan et al., that reported that the mean CSA in CTS patients and the control group to be $12.7 \mathrm{~mm} 2$ and $7 \mathrm{~mm} 2$, respectively. Such results variability may be attributed to different study design measurement techniques or due to exclusion of patient with mild electrodiagnostic test

Buchberger., et al (20) recorded the mean median nerve CSA at proximal tunnel $14.5 \mathrm{~mm} 2$ (range,8.8$20.5 \mathrm{~mm} 2 ; \mathrm{SD}, 3.8 \mathrm{~mm} 2)$. The mean flattening ratio was 2.7 range, 2.0-3.7; SD, 0.4) at pisiform bone. The flexor retinaculum bowing (mean $3.7 \mathrm{~mm}$; range, $2.0-6.0 \mathrm{~mm}$; SD, $1.1 \mathrm{~mm}$ ). So, our study showed that all patient diagnosed by CTS fall in the same range described by Buchberger with mean CSA $14.96 \mathrm{~mm} 2+/$ 4.2 ranging (4-24 mm2), Mean Bowing index was $15.11+/-4.42$ _ ranging (8.32 - 27.00) and mean Flattening ratio was $2.97+/-0.69$ and ranged $1.54-4.20$. Bowing index even showed higher value in our 
study as most of our patients were diabetic with high percentage of them showed tenosynovitis, tunnel interstitial edema and tissue swelling.

Sonographically, we found that using CSA was the most frequently occurring parameter, as it was positive in $93.7 \%$ of our patients, followed by decrease nerve echo texture $(90.6 \%)$. Unfortunately, there is no studies in literature to evaluate the diagnostic capability of retinacular bowing index and flattening index of median nerve as separate diagnostic parameters in CTS, however at our study they were recorded positive in $59.4 \%$ for each in US, denoting relatively low predictive value compared to the CSA and nerve echotexture changes

Magnetic resonance Neurography is an excellent modality for soft tissue contrast, allowing detection of subtle abnormalities as T2 increased signal within nerve fibers and fascicular pattern. Yet, isolated magnetic resonance sign of nerve high T2 signal showed specificity less than $40 \%$. Therefore, using additional MRN signs and parameters of neuropathy, i.e enlarged nerve $(>10-11 \mathrm{~mm} 2)$ proximal to the tunnel and at the level of pisiform bone, nerve flattening at the level of the hook of the hamate at the distal tunnel and retinaculum palmar bowing add to MRN specificity in detection of CTS. Effaced carpal tunnel fat and thenar muscle denervational edema may be seen as secondary findings of compressed median nerve (16). Pasternak., et al proved that MRI as diagnostic tool using increased T2-signal, CSA, distal nerve flattening \& retinaculum bowing were the most frequently occurring signs in CTS. our study showed that occurrence of these parameters was $90.6 \%, 81.2 \%, 56.2 \% \& 56.2$ respectively.

Kim et al, 2011 reached to a conclusion that MRI was more sensitive in detection of muscle denervation changes in form of high signal intensity. These changes progress from acute (edema-like T2 signal intensity), sub-acute (muscle edema with early fatty changes and /or atrophy) to chronic (muscle atrophy and fatty changes). Add to it characterization of space occupying lesions, fibrotic changes or thickened fascia. We agreed with Kim et al, and concluded that US was able to diagnose muscle denervation changes in two cases only, while MRN was able to detect muscle denervation changes in $34.4 \%$ of patients, and underlying tunnel abnormalities in 15 patients out of 32, which prove the higher sensitivity of MRN in detection of secondary muscle changes of CTS. (Case 2)

In our study we tabulated agreement between MRI \& US regarding the three main parameters CSA, bowing and flattening indices and we reached to a result that US was better in detection of CTS using the three parameters with high significant statistical variability ( $p$ value 0.001 ).

The US was able to detect cause of the entrapment in about $31.2 \%$ of the cases and about $68.8 \%$ of the cases are considered of idiopathic cause, while MRN was able to detect cause of the entrapment in about $46.9 \%$ of the cases and about $53.1 \%$ of them are considered of idiopathic cause. Also noted the ability of MRI in diagnosis of muscle denervation changes as secondary sequel of nerve entrapment (Case 3 ). So, in the cases at which primary nerve abnormality could not be visualized by US, the detection of innervated muscle MRI signal changes could be used to diagnose and locate the nerve lesion, denoting higher sensitivity of MRN in detection of secondary causes and muscle denervation changes with highly statistically significant difference. 
Our results agree with Martinoli et al., who found that US results was comparable to MRN in diagnosis of CTS. Yet, MRI was superior to US in recognizing subtle changes, as neural signal changes caused by edema and blood perfusion changes. Also, we agreed with Thawait K., et al (25) who proved that MRN could support the clinical data, giving information about the nature of the underlying nerve lesion, defining its site and extent, with better intra-neural fascicular pattern assessment, and providing an overview of surrounding oft tissue and regional muscle abnormalities.

\section{Conclusion}

We could conclude that ultrasound examination can be used as first imaging step after physician evaluation with comparable results to electrophysiological studies in evaluating CTS and try to find the cause. MRN examination came as second step in patients with suspected muscle denervation changes that could not be elicited by US or equivocal cases for detection of secondary cause in clinically suspected patient.

\section{Abbreviations}

CTS: carpal tunnel syndrome;

CSA: cross sectional area

\section{Declarations}

\section{Ethics approval and consent to participate}

A written informed consent was obtained from all participants, methods were carried out in accordance with relevant guidelines \& regulations. The study is approved by Faculty of medicine, Ain Shams University Ethical committee with approval number [Fmasu R163/2021].

All patients' data is deidentified \& research will involve only MRI \& US images.

\section{Consent for publication}

Not applicable

\section{Availability of data and material}

The authors declare that all other data supporting the findings of this study are available within the article

\section{Competing interests}

The authors declare that they have no competing interests 


\section{Funding}

The authors received no financial support for the research, authorship, and/or publication of this article.

\section{Authors' contributions}

Author 1 : Dr. MGA collected the data, Wrote the paper and organized the material

Author 2: Dr. EFD conceived and designed analysis, shared in paper writing, contributed in data and analysis tools

All authors have read and approved the manuscript

\section{Acknowledgements}

No acknowledgment .

\section{References}

1- Su-Jin Kim, Sung Hwan Hong, Woo Sun Jun, Ja-Young Choi, Jae Sung Myung, Jon A. Jacobson, Joon Woo Lee, Jung-Ah Choi and Heung Sik Kang. MR Imaging mapping of skeletal muscle denervation in entrapment and compressive neuropathies. RadioGraphics. 2011; 31: 319-332. DOI:

$10.1148 /$ rg.312105122

2- Philippe Meyer,Pierre-Francois Lintingre,Lionel Pesquer,Nicolas Poussange,Alain Silvestre, and Benjamin Dallaudière, The Median Nerve at the Carpal Tunnel and Elsewhere. J Belg Soc Radiol. 2018; 102(1): 17.

3-A. Deniela, A.CauseretaT., MoserbY. Roll,T.Dréano and R.Guillina,. Entrapment and traumatic neuropathies of the elbow and hand: An imaging approach. Journal de Radiologie Diagnostique et Interventionnelle, Volume 96, Issue 6, December 2015, Pages 545-563

4- Dorota Dominika Linda, Srinivasan Harish, Brian G. Stewart, Karen Finlay, Naveen Parasu, Ryan Paul Rebello. Multimodality Imaging of Peripheral Neuropathies of the Upper Limb and Brachial Plexus. RadioGraphics 2010; 30:1373-1400

5- Christian Dejaco, Martin Stradner, Dorothea Zauner, Werner Seel, Nicole Elisabeth Simmet, Alexander Klammer, Petra Heitzer, Kerstin Brickmann, Judith Gretler, Florentine C Fürst-Moazedi, Rene Thonhofer, Rusmir Husic, Josef Hermann, Winfried B Graninger and Stefan Quasthoff. Ultrasound for diagnosis of carpal tunnel syndrome: comparison of different methods to determine median nerve volume and value of power doppler sonography. Ann Rheum Dis. 2013; 72: 1934-1939.

6- Martinoli C, Bianchi S, Gandolfo N, Valle M, Simonetti S, Derchi LE. US of nerve entrapments in osteofibrous tunnels of the upper and lower limbs. Radio-Graphics 2000;20(Spec No): S199-S213; discussion 
7- Andreisek G, Burg D, Studer A, Weishaupt D., Upper extremity peripheral neuropathies: role and impact of MR imaging on patient management. Eur Radiol 2008;18(9):1953-1961

8- Ghasemi-Esfe, AR, Khalilzadeh, O, Vaziri-Bozorg, SM, Jajroudi, M, Shakiba, M, et al. Color and Power Doppler US for diagnosing Carpal Tunnel Syndrome and determining its severity: A quantitative image processing method. Radiology. 2011; 261: 499-506.

9- Hideaki Miyamoto, Ethan J Halpern, Martin Kastlunger, Markus Gabl, Rohit Arora, Rosa BellmannWeiler, Gudrun M Feuchtner, Werner R Jaschke and Andrea S Klauser. Carpal Tunnel Syndrome: Diagnosis by Means of Median Nerve Elasticity-Improved Diagnostic Accurracy of US with Sonoelastography. Radiology. 2014; 270: 481-486.

10-Andrea S. Klauser, Ethan J. Halpern, Ralph Faschingbauer, Florian Guerra, Carlo Martinoli, Markus F. Gabl, Rohit Arora,Thomas Bauer, Martin Sojer, Wolfgang N. Löscher, Werner R. Jaschke. Bifid Medain Nerve in Carpal Tunnel Syndrome: Assessment with US Cross-sectional Area Measurements. Radiology. 2011; 259: 808-815.

11 Nagano A., Spontaneous anterior interosseous nerve palsy. J Bone Joint Surg Br. 2003; 85: 313-318.

12- Chin Chin Ooi, Siew Kune Wong, Agnes B H Tan, Andrew Y H Chin, Rafidah Abu Bakar, Shy Yunn Goh, P Chandra Mohan, Robert T J Yap and Meng Ai Png. Diagnostic criteria of carpal tunnel syndrome using high-resolution ultrasonography: correlation with nerve conduction studies. Skeletal Radiol, 43 (2014), pp. 1387-1394

13- Theodore T. Miller and William R. Reinus. Nerve Entrapment Syndromes of the Elbow, Forearm, and Wrist. AJR 2010; 195:585 - 594

14- Fatih Ersay Deniz, Erol Öksüz, Bas,ar Sarikaya, Semiha Kurt, Ünal Erkorkmaz, Hasan Ulusoy and Șule Arslan. Comparison of the Diagnostic Utility of Electromyography, Ultrasonography, Computed Tomography, and Magnetic Resonance Imaging in Idiopathic Carpal Tunnel Syndrome Determined by Clinical Findings. Neurosurgery, Volume 70, Issue 3, 1 March 2012, Pages 610-616.

15- Roman Guggenberger, Daniel Markovic, Patrick Eppenberger, Avneesh Chhabra, Andreas Schiller, Daniel Nanz, Klaas Prüssmann and Gustav Andreisek, Assessment of Median nerve with MR-neurography by Using Diffusion-Tensor imaging: Normative and Pathologic Diffusion Values. Radiology 2012; 265:194-203

16- Seror P., Sonography and electrodiagnosis in carpal tunnel syndrome diagnosis: an analysis of the literature. Eur J Radiol 2008;67(1):146-152.

17- Wong SM, Griffith JF, Hui AC, Lo SK, Fu M and Wong KS., Carpal tunnel syndrome: diagnostic usefulness of sonography. Radiology2004;232(1):93-99. 
18- Pasternack II, Malmivaara A, Tervahartiala P, Forsberg H and Vehmas T. Magnetic resonance imaging findings in respect to carpal tunnel syndrome. Scand J Work Environ Health 2003;29(3):189-196

19- Siegfried Peer, Hannes Gruber and Alexander Loizides, Sonography of carpal tunnel syndrome: why, when and how. Imaging Med. (2012) 4(3), 287-297 ISSN 1755-5191

20 W Buchberger, W Judmaier, G Birbamer, M Lener and C Schmidauer. Carpal Tunnel Syndrome: Diagnosis with High-Resolution Sonograph. AJR 159:793-798, October 1992

21- M. Rahmani, A. R. Ghasemi Esfe, S. M. Bozorg, M. Mazloumi,O. Khalilzadeh \&

H. Kahnouji . The ultrasonographic correlates of carpal tunnel syndrome in patients with normal electrodiagnostic tests. Radiol med 116, 489-496 (2011).

22- Özlen Karabulut; Mehmet Cudi Tuncer; Zülfü Karabulut \& Ebru Güzel. Analysis of MR Imaging of Wrists in Female Patients with Carpal Tunnel Syndrome and Healthy Controls. Int. J. Morphol.,27(3):791800, 2009.

23 A.Yesildaga, S.Kutluhanb, N.Sengula, H.R.Koyuncuoglub, O.OyaraK, GulerbU. and K.Gulsoya. The role of ultrasonographic measurements of the median nerve in the diagnosis of carpal tunnel syndrome. Clinical Radiology 2004 Oct;59(10):910-5

24- Lain Duncan, Paul Sullivan and Fred Lomas. Sonography in the Diagnosis of Carpal Tunnel Syndrome. AJR1999:173:681-684

25- S.K. Thawait, K. Wang, T.K. Subhawong, E.H. Williams, S.S. Hashemi, A.J. Machado, G.K. Thawait, T. Soldatos, J.A. Carrino and A. Chhabra. Peripheral Nerve Surgery: The Role of High-Resolution MR Neurography. AJNR Am J Neuroradiol 2012 Feb;33(2):203-10

\section{Tables}

Table (1): Characteristics and clinical picture in the studied participants $(n=32)$ 


\begin{tabular}{|c|c|c|c|c|}
\hline Variables & & No. & & $\%$ \\
\hline \multirow[t]{2}{*}{ Sex } & Male & 12 & & $37.5 \%$ \\
\hline & Female & 20 & & $62.5 \%$ \\
\hline \multirow[t]{3}{*}{ Age } & & Mean & $\pm \mathrm{SD}$ & Range \\
\hline & & 43.25 & 13.99 & $18.00-67.00$ \\
\hline & & No. & & $\%$ \\
\hline \multirow[t]{5}{*}{ Work } & House wife & 16 & & $50.0 \%$ \\
\hline & Handworker (e.g Carpenter, Farmer) & 11 & & $34.4 \%$ \\
\hline & Gymnast & 2 & & $6.2 \%$ \\
\hline & Nurse & 1 & & $3.1 \%$ \\
\hline & Employee & 2 & & $6.2 \%$ \\
\hline \multirow[t]{4}{*}{ Comorbidity } & No comorbidity & 20 & & $62.5 \%$ \\
\hline & DM & 6 & & $18.8 \%$ \\
\hline & RA & 4 & & $12.5 \%$ \\
\hline & Wrist cut wound & 2 & & $6.2 \%$ \\
\hline \multirow[t]{2}{*}{ Side } & Rt & 26 & & $81.2 \%$ \\
\hline & $\mathrm{Lt}$ & 6 & & $18.8 \%$ \\
\hline \multirow[t]{2}{*}{ Pain } & No & 0 & & $0.0 \%$ \\
\hline & Yes & 32 & & $100.0 \%$ \\
\hline \multirow[t]{2}{*}{ Paresthesia } & No & 11 & & $34.4 \%$ \\
\hline & Yes & 21 & & $65.6 \%$ \\
\hline
\end{tabular}

Table (2): Electrophysiological study and EMG muscle wasting ( $n=32)$ 


\begin{tabular}{|llll|}
\hline Variables & \multicolumn{2}{c|}{ No. } & $\%$ \\
\hline $\begin{array}{l}\text { Electrophysiological } \\
\text { study }\end{array}$ & Minimal neuropathy at wrist level & 6 & $18.8 \%$ \\
\cline { 2 - 4 } & Mild neuropathy at wrist level & 11 & $34.4 \%$ \\
\cline { 2 - 4 } & Moderate neuropathy at wrist level & 8 & $25.0 \%$ \\
\hline & Severe neuropathy at wrist level & 2 & $6.2 \%$ \\
\hline & $\begin{array}{l}\text { Severe neuropathy at wrist level with muscle } \\
\text { denervation }\end{array}$ & 5 & $15.6 \%$ \\
\hline EMG Muscle wasting & No & 23 & $71.9 \%$ \\
\cline { 2 - 4 } & Yes & 9 & $28.1 \%$ \\
\hline
\end{tabular}

Table (3): U/S findings in the studied participants $(n=32)$

\begin{tabular}{|llll|}
\hline Variables & & No. & $\%$ \\
\hline U/S Echogenicity & No & 3 & $9.4 \%$ \\
\cline { 2 - 4 } U/S CSA & Yes & 29 & $90.6 \%$ \\
\hline U/S Bowing index & Normal & 2 & $6.2 \%$ \\
\cline { 2 - 4 } & Increased & 30 & $93.8 \%$ \\
\hline U/S Flattening index & Normal & 13 & $40.6 \%$ \\
\cline { 2 - 4 } & Increased & 19 & $59.4 \%$ \\
\hline U/S Muscle atrophic changes & Normal & 13 & $40.6 \%$ \\
\cline { 2 - 4 } & Increased & 19 & $59.4 \%$ \\
\cline { 2 - 4 } Abnormality by U/S & Yes & 30 & $93.8 \%$ \\
\hline Type of Abnormality & No abnormality & 22 & $68.8 \%$ \\
\hline (n=10) & Abnormality & 10 & $31.2 \%$ \\
\hline & Tenosynovitis & 6 & $60.0 \%$ \\
\cline { 2 - 4 } & NIC & 2 & $20.0 \%$ \\
\hline & Synovial Hypertrophy & 2 & $20.0 \%$ \\
\hline
\end{tabular}

Table (4): U/S Measurements in the studied patients 


\begin{tabular}{|lccll|}
\hline & Mean & $\mathbf{\pm}$ SD & Minimum & Maximum \\
\hline U/S CSA & 14.96 & 4.42 & 4.00 & 23.00 \\
\hline Bowing index size & 15.11 & 4.42 & 8.32 & 27.00 \\
\hline Flattening index size & 2.97 & .69 & 1.54 & 4.20 \\
\hline
\end{tabular}

Table (5): MRI findings in the studied participants $(n=32)$

\begin{tabular}{|c|c|c|c|}
\hline Variables & & No. & $\%$ \\
\hline \multirow[t]{2}{*}{ MRI Increased T2 Signal } & No & 3 & $9.4 \%$ \\
\hline & Yes & 29 & $90.6 \%$ \\
\hline \multirow[t]{2}{*}{ MRI Proximal CSA } & No & 6 & $18.8 \%$ \\
\hline & Yes & 26 & $81.2 \%$ \\
\hline \multirow[t]{2}{*}{ MRI Distal Flattening } & No & 14 & $43.8 \%$ \\
\hline & Yes & 18 & $56.2 \%$ \\
\hline \multirow[t]{2}{*}{ MRI Bowing } & No & 14 & $43.8 \%$ \\
\hline & Yes & 18 & $56.2 \%$ \\
\hline \multirow[t]{2}{*}{ MRI Fascular pattern } & No & 30 & $93.8 \%$ \\
\hline & Yes & 2 & $6.2 \%$ \\
\hline \multirow[t]{2}{*}{ MRI Signal alteration } & No & 21 & $65.6 \%$ \\
\hline & Yes & 11 & $34.4 \%$ \\
\hline \multirow[t]{2}{*}{ Abnormality by MRI } & No abnormality & 17 & $53.1 \%$ \\
\hline & Abnormality & 15 & $46.9 \%$ \\
\hline \multirow{4}{*}{$\begin{array}{l}\text { Type of Abnormality } \\
(n=15)\end{array}$} & Tenosynovitis & 8 & $53.3 \%$ \\
\hline & Ganglion cyst & 3 & $20.0 \%$ \\
\hline & Minimal edema of the tunnel & 2 & $13.3 \%$ \\
\hline & Traumatic neuroma & 2 & $13.3 \%$ \\
\hline
\end{tabular}

Table (6): Agreement between MRI and U/S regarding CSA in Carpal tunnel syndrome patients $(n=32)$ 


\begin{tabular}{|c|c|c|c|c|c|c|c|}
\hline & & & \multicolumn{2}{|c|}{ MRI_Proximal_CSA } & \multirow[t]{2}{*}{ Total } & \multirow[t]{2}{*}{ Kappa } & \multirow{2}{*}{$\begin{array}{l}\mathrm{P}- \\
\text { value }\end{array}$} \\
\hline & & & No & Yes & & & \\
\hline \multirow{6}{*}{$\begin{array}{l}\text { US } \\
\text { CSA }\end{array}$} & \multirow[t]{3}{*}{ Normal } & No. & 2 & 0 & 2 & \multirow[t]{9}{*}{0.448} & \multirow[t]{9}{*}{$0.002 *$} \\
\hline & & $\%$ within US CSA & $100.0 \%$ & $0.0 \%$ & $100.0 \%$ & & \\
\hline & & $\begin{array}{l}\text { \% within MRI Proximal } \\
\text { CSA }\end{array}$ & $33.3 \%$ & $0.0 \%$ & $6.2 \%$ & & \\
\hline & \multirow[t]{3}{*}{ Increased } & No. & 4 & 26 & 30 & & \\
\hline & & $\%$ within US CSA & $13.3 \%$ & $86.7 \%$ & $100.0 \%$ & & \\
\hline & & $\begin{array}{l}\text { \% within MRI Proximal } \\
\text { CSA }\end{array}$ & $66.7 \%$ & $100.0 \%$ & $93.8 \%$ & & \\
\hline \multirow[t]{3}{*}{ Total } & & No. & 6 & 26 & 32 & & \\
\hline & & $\%$ within US CSA & $18.8 \%$ & $81.2 \%$ & $100.0 \%$ & & \\
\hline & & $\begin{array}{l}\text { \% within MRI Proximal } \\
\text { CSA }\end{array}$ & $100.0 \%$ & $100.0 \%$ & $100.0 \%$ & & \\
\hline
\end{tabular}

Table (7): Agreement between MRI and U/S regarding Bowing index in Carpal tunnel syndrome patients (n=32)

\begin{tabular}{|c|c|c|c|c|c|c|c|}
\hline & & & \multicolumn{2}{|c|}{ MRI_Bowing } & \multirow[t]{2}{*}{ Total } & \multirow[t]{2}{*}{ Kappa } & \multirow[t]{2}{*}{ P-value } \\
\hline & & & No & Yes & & & \\
\hline \multirow{6}{*}{$\begin{array}{l}\text { U/S Bowing } \\
\text { index }\end{array}$} & \multirow[t]{3}{*}{ Normal } & No. & 12 & 1 & 13 & \multirow[t]{9}{*}{0.808} & \multirow[t]{9}{*}{$0.000 * \star$} \\
\hline & & $\begin{array}{l}\text { \% within } \\
\text { Bowing_index }\end{array}$ & $92.3 \%$ & $7.7 \%$ & $100.0 \%$ & & \\
\hline & & $\begin{array}{l}\text { \% within } \\
\text { MRI_Bowing }\end{array}$ & $85.7 \%$ & $5.6 \%$ & $40.6 \%$ & & \\
\hline & \multirow[t]{3}{*}{ Increased } & No. & 2 & 17 & 19 & & \\
\hline & & $\begin{array}{l}\text { \% within } \\
\text { Bowing_index }\end{array}$ & $10.5 \%$ & $89.5 \%$ & $100.0 \%$ & & \\
\hline & & $\begin{array}{l}\text { \% within } \\
\text { MRI_Bowing }\end{array}$ & $14.3 \%$ & $94.4 \%$ & $59.4 \%$ & & \\
\hline \multirow[t]{3}{*}{ Total } & & No. & 14 & 18 & 32 & & \\
\hline & & $\begin{array}{l}\text { \% within } \\
\text { Bowing_index }\end{array}$ & $43.8 \%$ & $56.2 \%$ & $100.0 \%$ & & \\
\hline & & $\begin{array}{l}\text { \% within } \\
\text { MRI_Bowing }\end{array}$ & $100.0 \%$ & $100.0 \%$ & $100.0 \%$ & & \\
\hline
\end{tabular}


Table (8): Agreement between MRI and U/S regarding Distal flattening in Carpal tunnel syndrome patients $(n=32)$

\begin{tabular}{|c|c|c|c|c|c|c|c|}
\hline & & & \multicolumn{2}{|c|}{$\begin{array}{l}\text { MRI Distal } \\
\text { Flattening }\end{array}$} & \multirow[t]{2}{*}{ Total } & \multirow[t]{3}{*}{ Kappa } & \multirow[t]{3}{*}{ P-value } \\
\hline & & & No & Yes & & & \\
\hline \multirow{6}{*}{$\begin{array}{l}\text { Flattening } \\
\text { index }\end{array}$} & \multirow[t]{3}{*}{ Normal } & No. & 11 & 2 & 13 & & \\
\hline & & $\begin{array}{l}\text { \% within Flattening } \\
\text { index }\end{array}$ & $84.6 \%$ & $15.4 \%$ & $100.0 \%$ & \multirow[t]{8}{*}{0.680} & \multirow[t]{8}{*}{$0.000 * \star$} \\
\hline & & $\begin{array}{l}\text { \% within MRI Distal } \\
\text { Flattening }\end{array}$ & $78.6 \%$ & $11.1 \%$ & $40.6 \%$ & & \\
\hline & \multirow[t]{3}{*}{ Increased } & No. & 3 & 16 & 19 & & \\
\hline & & $\begin{array}{l}\text { \% within Flattening } \\
\text { index }\end{array}$ & $15.8 \%$ & $84.2 \%$ & $100.0 \%$ & & \\
\hline & & $\begin{array}{l}\text { \% within MRI Distal } \\
\text { Flattening }\end{array}$ & $21.4 \%$ & $88.9 \%$ & $59.4 \%$ & & \\
\hline \multirow[t]{3}{*}{ Total } & & No. & 14 & 18 & 32 & & \\
\hline & & $\begin{array}{l}\text { \% within Flattening } \\
\text { index }\end{array}$ & $43.8 \%$ & $56.2 \%$ & $100.0 \%$ & & \\
\hline & & $\begin{array}{l}\text { \% within MRI Distal } \\
\text { Flattening }\end{array}$ & $100.0 \%$ & $100.0 \%$ & $100.0 \%$ & & \\
\hline
\end{tabular}

Table (9): Agreement between MRI and U/S regarding diagnosis of CAUSE of Carpal tunnel syndrome $(n=32)$ 


\begin{tabular}{|c|c|c|c|c|c|c|c|}
\hline & & & \multicolumn{2}{|l|}{ MRI } & \multirow[t]{2}{*}{ Total } & \multirow[t]{2}{*}{ Kappa } & \multirow[t]{2}{*}{ P-value } \\
\hline & & & $\begin{array}{l}\text { No } \\
\text { abnormality }\end{array}$ & Abnormality & & & \\
\hline \multirow[t]{6}{*}{ US } & \multirow{3}{*}{$\begin{array}{l}\text { No } \\
\text { abnormality }\end{array}$} & No. & 17 & 5 & 22 & \multirow[t]{9}{*}{0.680} & \multirow[t]{9}{*}{$0.000 * *$} \\
\hline & & \% within US & $77.3 \%$ & $22.7 \%$ & $100.0 \%$ & & \\
\hline & & $\begin{array}{l}\text { \% within } \\
\text { MRI }\end{array}$ & $100.0 \%$ & $33.3 \%$ & $68.8 \%$ & & \\
\hline & \multirow[t]{3}{*}{ Abnormality } & No. & 0 & 10 & 10 & & \\
\hline & & \% within US & $0.0 \%$ & $100.0 \%$ & $100.0 \%$ & & \\
\hline & & $\begin{array}{l}\text { \% within } \\
\text { MRI }\end{array}$ & $0.0 \%$ & $66.7 \%$ & $31.2 \%$ & & \\
\hline \multirow{3}{*}{\multicolumn{2}{|c|}{ Total }} & No. & 17 & 15 & 32 & & \\
\hline & & \% within US & $53.1 \%$ & $46.9 \%$ & $100.0 \%$ & & \\
\hline & & $\begin{array}{l}\text { \% within } \\
\text { MRI }\end{array}$ & $100.0 \%$ & $100.0 \%$ & $100.0 \%$ & & \\
\hline
\end{tabular}

Sensitivity of U/S $=10 / 32 * 100=31.25 \%$

Sensitivity of MRI $=15 / 32 * 100=46.8 \%$

Figures 


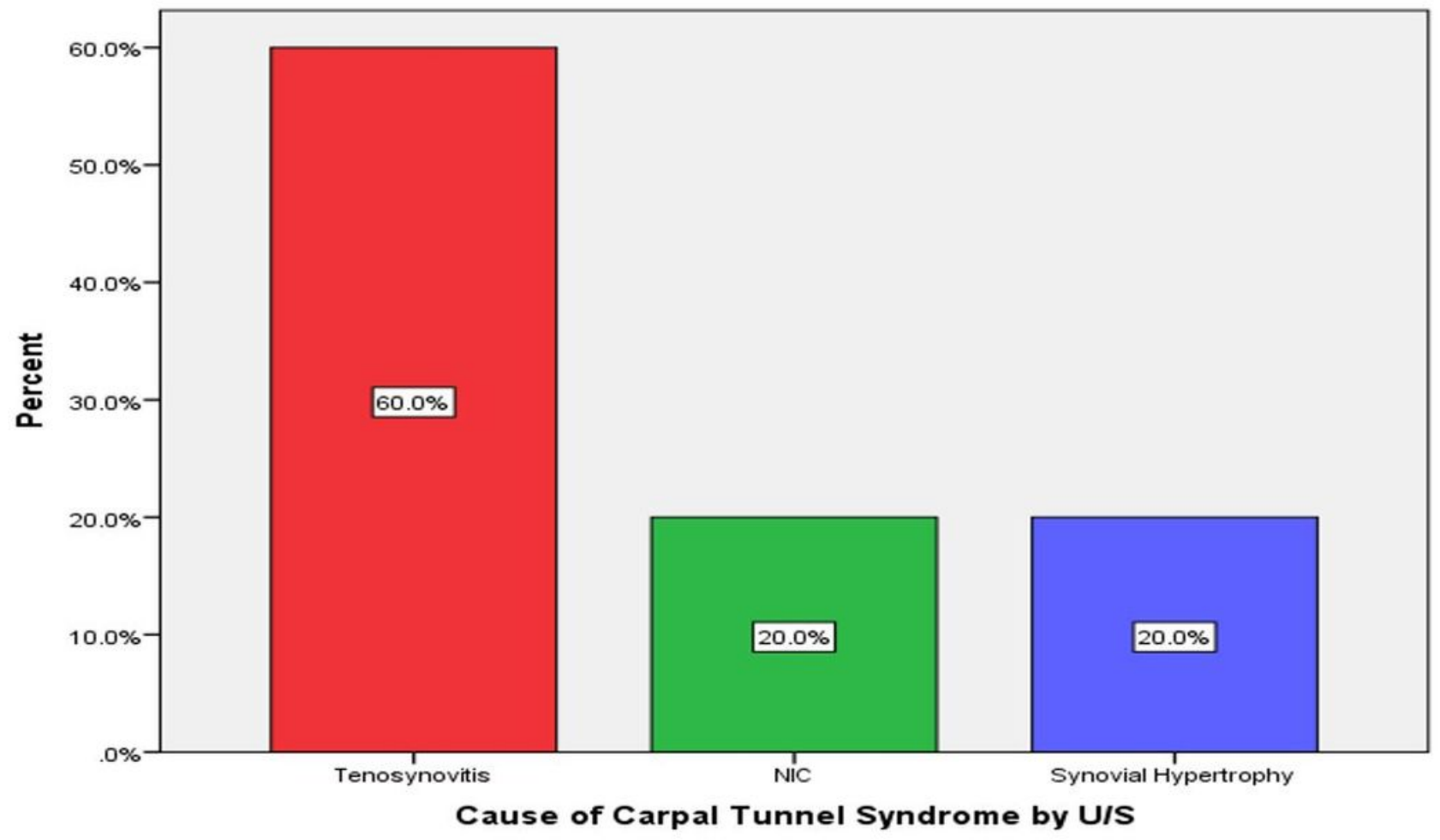

Figure 1

causes of Carpal tunnel syndrome by US 


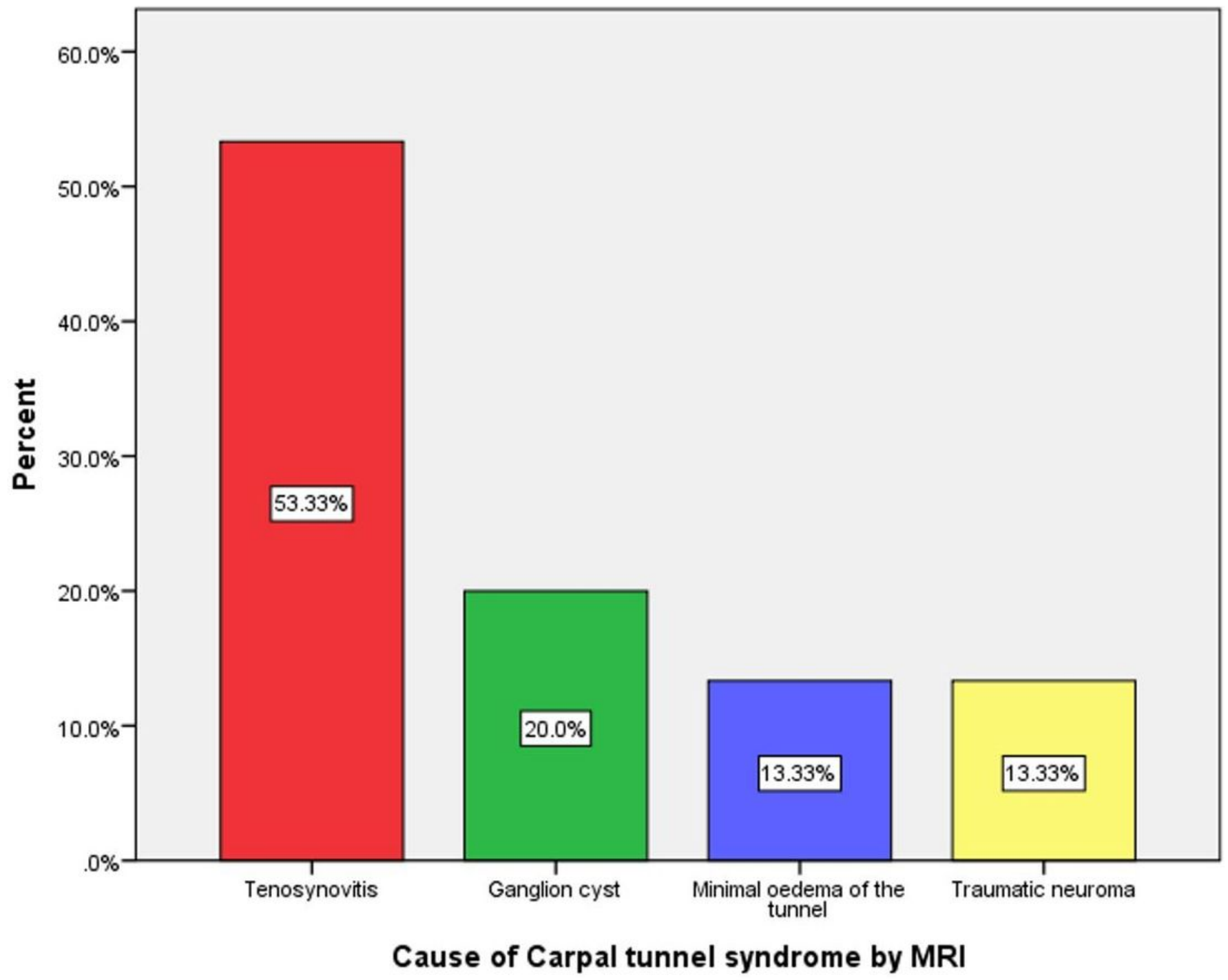

Figure 2

Causes of Carpal tunnel syndrome by MRI

\section{Supplementary Files}

This is a list of supplementary files associated with this preprint. Click to download.

- papercases.docx 